\title{
Two-Dimensional Aggregation and Semi-Dilute Ordering in Cellulose Nanocrystals
}

Martin Uhlig, ${ }^{\dagger}$ Andreas Fall, ${ }^{\ddagger}$ Stefan Wellert, ${ }^{\dagger}$ Maren Lehmann, ${ }^{\dagger}$ Sylvain Prévost,, Lars Wågberg, ${ }^{\dagger}$ Regine v. Klitzing, ${ }^{\dagger}$ and Gustav Nyström ${ }^{*}+\ddagger$

$\dagger$ Stranski-Laboratorium, Department of Chemistry, Technische Universität Berlin, Strasse des 17.Juni 124 D-10623 Berlin, Germany

$\ddagger$ Department of Fibre and Polymer Technology, and Wallenberg Wood Science Centre, KTH Royal Institute of Technology, School of Chemical Science and Engineering Teknikringen 56, 10044 Stockholm, Sweden

IESRF - The European Synchrotron, 71, avenue des Martyrs, 38000, Grenoble, France

E-mail: gustavn@kth.se

Phone: +414463203 60. Fax: +41446321603

\section{Supporting Information}

\section{SANS fit Parameters and extended data}

For both CNC-COOH and CNC-SO 3 H a Scattering Length Density (SLD) of $1.96 \cdot 10^{10}$ $\mathrm{cm}^{-2}$ was used. This SLD was calculated with the SLD calculator of the SASfit software (Kohlbrecher, J.; Bressler I. http://sasfit.ingobressler.net) using the chemical structure of cellulose $\left(\mathrm{C}_{12} \mathrm{H}_{20} \mathrm{O}_{10}\right)$ and the density $1.676 \mathrm{~g} / \mathrm{cm}^{3}$ (Nishiyama, Y. ; Langan, P. ; Chanzy, 
H. Crystal Structure and Hydrogen-Bonding System in Cellulose I $\beta$ from Synchrotron X-ray and Neutron Fiber Diffraction J. Am. Chem. Soc. 2002, 124, 9074-9082) The SLD of the solvent changed (due to the differing $\mathrm{D}_{2} \mathrm{O} / \mathrm{H}_{2} \mathrm{O}$ ratio). The resulting Scattering Length Density Contrasts (SLDC) (SLD[Solvent]-SLD[Cellulose]) can be found in Table 1 and Table 2 respectively.

Table 1: Scattering Length Density Contrasts (SLDC) of the investigated CNC-COOH samples.

\begin{tabular}{|c|c|c|c|c|c|c|c|c|c|}
\hline $\mathrm{c}_{\mathrm{CNC}-\mathrm{COOH}}[\mathrm{g} / \mathrm{L}]$ & 0.9 & 2.1 & 4.3 & 6.3 & 8.5 & 10.9 & 17 & 25.2 & 29.8 \\
\hline $\mathrm{SLDC}\left[10^{10} \cdot \mathrm{cm}^{-2}\right]$ & 4.61 & 4.58 & 4.53 & 4.49 & 4.45 & 4.43 & 4.36 & 4.35 & 4.28 \\
\hline
\end{tabular}

Table 2: Scattering Length Density Contrasts (SLDC) of the investigated $\mathrm{CNC}_{-} \mathrm{SO}_{3} \mathrm{H}$ samples.

\begin{tabular}{|c|c|c|c|c|}
\hline $\mathrm{c}_{\mathrm{CNC}-S O_{3} \mathrm{H}}[\mathrm{g} / \mathrm{L}]$ & 2.3 & 9.1 & 27.3 & 45.5 \\
\hline $\mathrm{SLDC}\left[10^{10} \cdot \mathrm{cm}^{-2}\right]$ & 4.62 & 4.58 & 4.47 & 4.19 \\
\hline
\end{tabular}

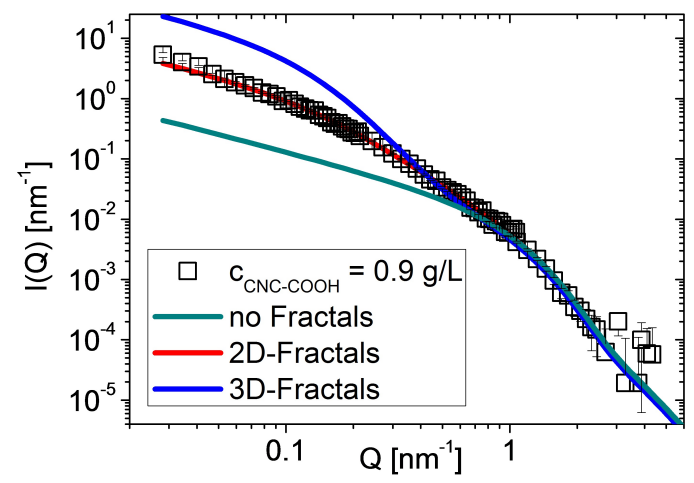

Figure 1: Long rod model with and without fractals applied.

To describe the polydispersity in radius of the rods a log normal distribution was used. Here $N$ corresponds to the number density, $s$ is the width parameter, $p$ the shape parameter and $\mu$ is the location parameter. Furthermore, the mass fractal model (here with experimental cutoff) was used to describe the aggregation of CNCs. It consists of the following parameters: $r_{0}$ characteristic dimension of individual scattering objects, $\xi$ cut-off length for the fractal correlations and the fractal dimension $D$. 


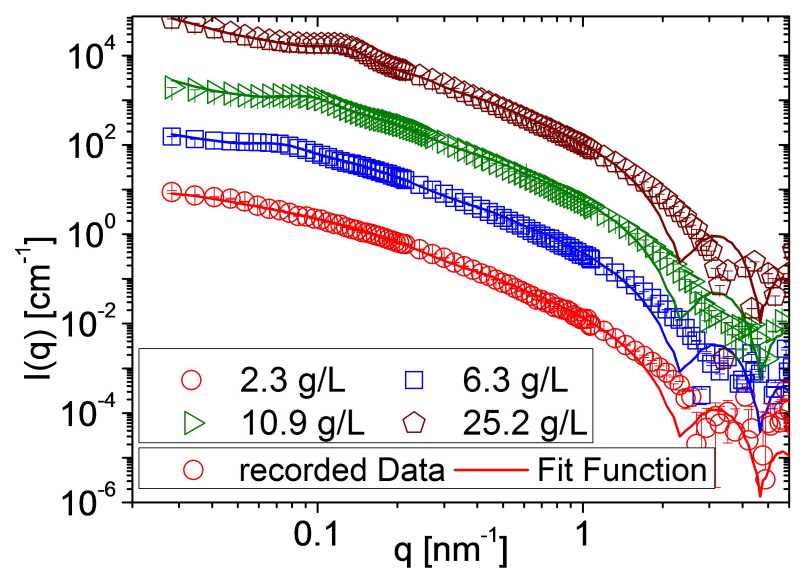

Figure 2: Additional SANS curves recorded for $\mathrm{CNC}-\mathrm{COOH}$ and fitted with the parallelepiped model. For better visibility curves are incrementally shifted by a factor of ten. The lowest concentration curve is in absolute scale.

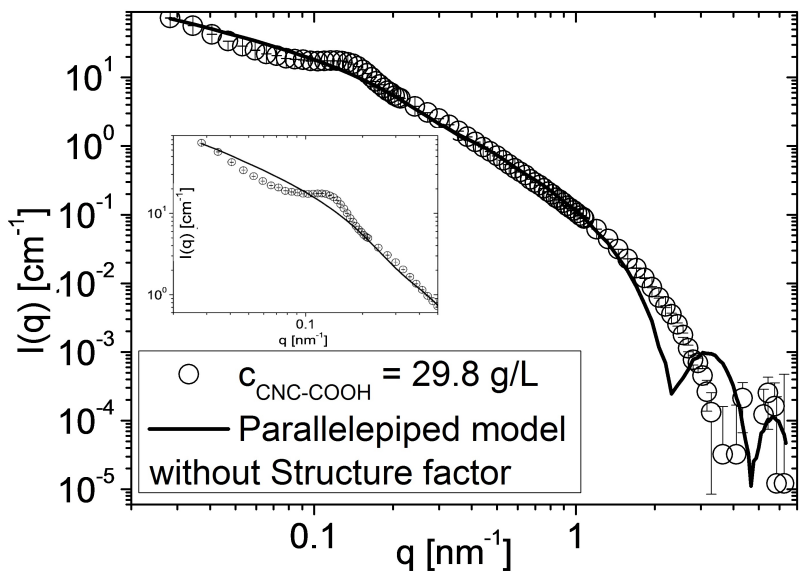

Figure 3: Fit with the parallelepiped model without the structure peak contribution for $\mathrm{CNC}-\mathrm{COOH} \mathrm{c}=29.8 \mathrm{~g} / \mathrm{L}$. In the inset the $Q$-Range around the peak is shown. 
Table 3: Fit parameters used for the long cylinder with fractals model for $\mathrm{CNC}-\mathrm{COOH}$ samples.

\begin{tabular}{|c|c|c|c|c|c|c|c|}
\hline Fit parameters & $s$ & $p$ & $\mu$ & $L$ & $r_{0}$ & $\xi$ & $D$ \\
\hline Values & 0.51 & 1 & 1.3 & 328 & 2.6 & 5.8 & 2.05 \\
\hline
\end{tabular}

Table 4: Concentrations and corresponding number densities used for the long cylinder with fractals model for $\mathrm{CNC}-\mathrm{COOH}$ samples.

\begin{tabular}{|c|c|c|c|c|c|c|c|c|c|}
\hline$c[\mathrm{~g} / \mathrm{L}]$ & 0.9 & 2.1 & 4.3 & 6.3 & 8.5 & 10.9 & 17 & 25.2 & 29.8 \\
\hline Number density $\left[10^{-7} \cdot \mathrm{nm}^{-3}\right]$ & 1.68 & 4.20 & 8.40 & 12.59 & 16.79 & 19.37 & 27.22 & 38.36 & 43.72 \\
\hline
\end{tabular}

Table 5: Fit parameters used for the long cylinder with fractals model for $\mathrm{CNC}_{-} \mathrm{SO}_{3} \mathrm{H}$ samples.

\begin{tabular}{|c|c|c|c|c|c|c|c|}
\hline Fit parameters & $s$ & $p$ & $\mu$ & $L$ & $r_{0}$ & $\xi$ & $D$ \\
\hline Values & 0.15 & 1 & 1.61 & 163 & 2.8 & 5.9 & 2.1 \\
\hline
\end{tabular}

Table 6: Concentrations and corresponding number densities used for the long cylinder with fractals model for $\mathrm{CNC}-\mathrm{SO}_{3} \mathrm{H}$ samples.

\begin{tabular}{|c|c|c|c|c|}
\hline$c[\mathrm{~g} / \mathrm{L}]$ & 2.3 & 9.1 & 27.3 & 45.5 \\
\hline Number density $\left[10^{-7} \cdot \mathrm{nm}^{-3}\right]$ & 3.43 & 13.72 & 41.17 & 58.56 \\
\hline
\end{tabular}

The modified Caillé model consist of the following parameters: $N$ total layers within the scattering domain, $d$ stacking separation of those layers, $\eta$ the Caillé parameter, which is a measure for bilayer bending fluctuations and $N u$ which is a scaling constant for the additional diffuse scattering term. As mentioned in the main text the fits were just qualitatively used to describe the scattering curves and instead a Lorentz fit of the structure factor $S(Q)$ was used to extract the distances. Thus, those parameters are just given for completeness. The two lowest CNC-COOH concentrations $(c=0.9$ and $2.1 \mathrm{~g} / \mathrm{L})$ did not show a structure peak. Therefore, they were fitted with the parallelepiped model without a structure factor. Due to the complexity of the parallelepiped model no error distribution was used here. Thus, the number density $N$ is used here as a scaling parameter without additional error models.

Table 7: Fit parameters used for the parallelepiped model with modified Caillé structure factor for $\mathrm{CNC}-\mathrm{COOH}$ samples.

\begin{tabular}{|c|c|c|c|c|}
\hline Fit parameters & $a$ & $b$ & $c$ & $N$ (modified Caillé) \\
\hline Values & 2.7 & 21.7 & 328 & 2.14 \\
\hline
\end{tabular}




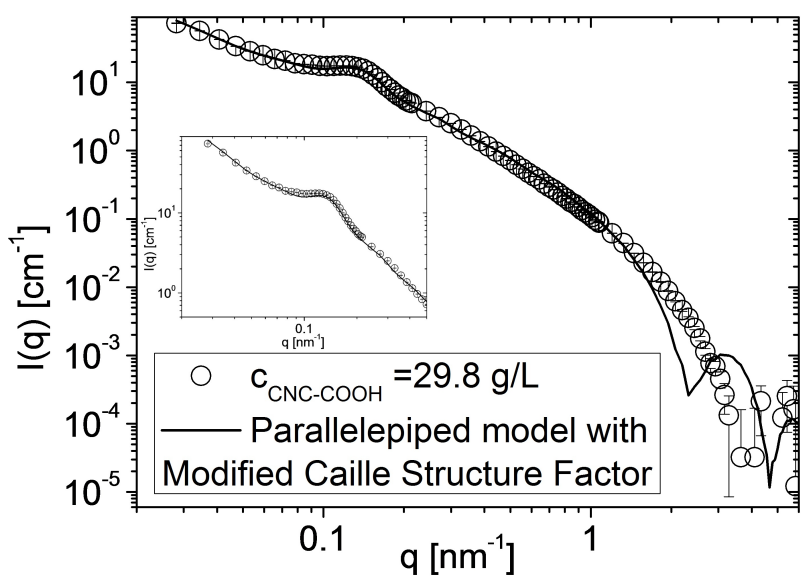

Figure 4: Fit with the parallelepiped model with the structure peak contribution (modified caile model) for $\mathrm{CNC}-\mathrm{COOH} \mathrm{c}=29.8 \mathrm{~g} / \mathrm{L}$. In the inset the $Q$-Range around the peak is shown.

Table 8: Concentrations, corresponding number densities and varying parameters of the modified Caillé structure factor used together with the parallelepiped model for CNC-COOH samples (Part1).

\begin{tabular}{|c|c|c|c|c|c|}
\hline $\mathrm{c}[\mathrm{g} / \mathrm{L}]$ & 0.9 & 2.1 & 4.3 & 6.3 & 8.5 \\
\hline Number density $\left[10^{-7} \cdot \mathrm{nm}^{-3}\right]$ & 0.16 & 0.4 & 0.2 & 0.3 & 0.4 \\
\hline$d[\mathrm{~nm}]$ & $/$ & $/$ & 95.1 & 77.1 & 67.2 \\
\hline$\eta$ & $/$ & $/$ & 0.96 & 0.97 & 0.80 \\
\hline$N u$ & $/$ & $/$ & 1.96 & 1.80 & 1.75 \\
\hline
\end{tabular}

Table 9: Concentrations, corresponding number densities and varying parameters of the modified Caillé structure factor used together with the parallelepiped model for $\mathrm{CNC}-\mathrm{COOH}$ samples (Part2).

\begin{tabular}{|c|c|c|c|c|}
\hline$c[\mathrm{~g} / \mathrm{L}]$ & 10.9 & 17 & 25.2 & 29.8 \\
\hline Number density $\left[10^{-7} \cdot \mathrm{nm}^{-3}\right]$ & 0.52 & 0.29 & 0.63 & 0.83 \\
\hline$d[\mathrm{~nm}]$ & 61.3 & 57.2 & 47.5 & 43.7 \\
\hline$\eta$ & 0.79 & 0.20 & 0.33 & 0.38 \\
\hline$N u$ & 1.42 & 6.17 & 3.41 & 2.60 \\
\hline
\end{tabular}

Table 10: Fit parameters used for the parallelepiped model with modified Caille structure factor for $\mathrm{CNC}-\mathrm{SO}_{3} \mathrm{H}$ samples.

\begin{tabular}{|c|c|c|c|c|}
\hline Fit parameters & $a$ & $b$ & $c$ & $N$ (modified Caillé) \\
\hline Values & 3 & 24.4 & 163 & 5.39 \\
\hline
\end{tabular}




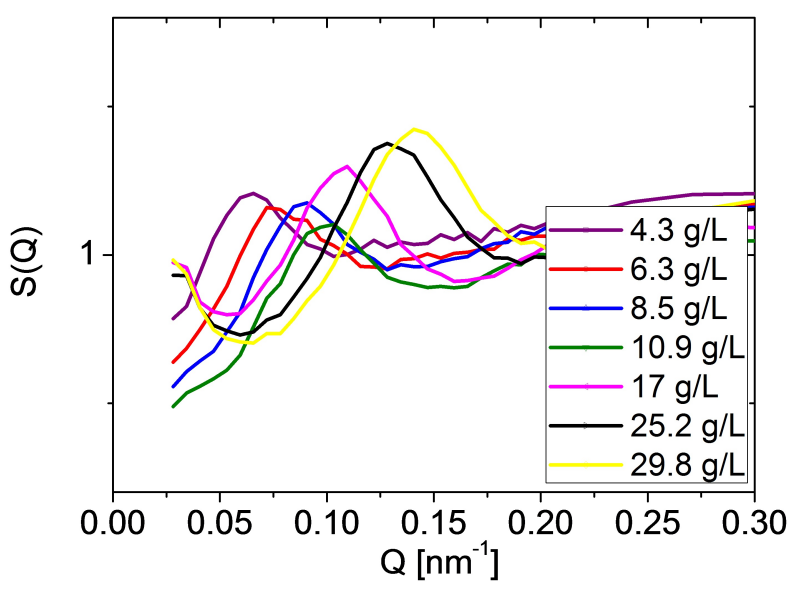

Figure 5: S(Q) for CNC-COOH.

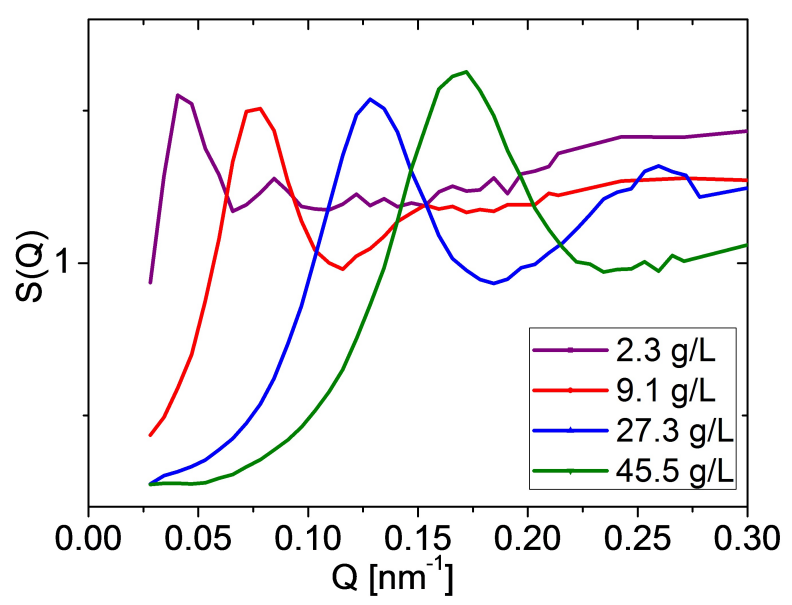

Figure 6: $\mathrm{S}(\mathrm{Q})$ for $\mathrm{CNC}_{-} \mathrm{SO}_{3} \mathrm{H}$.

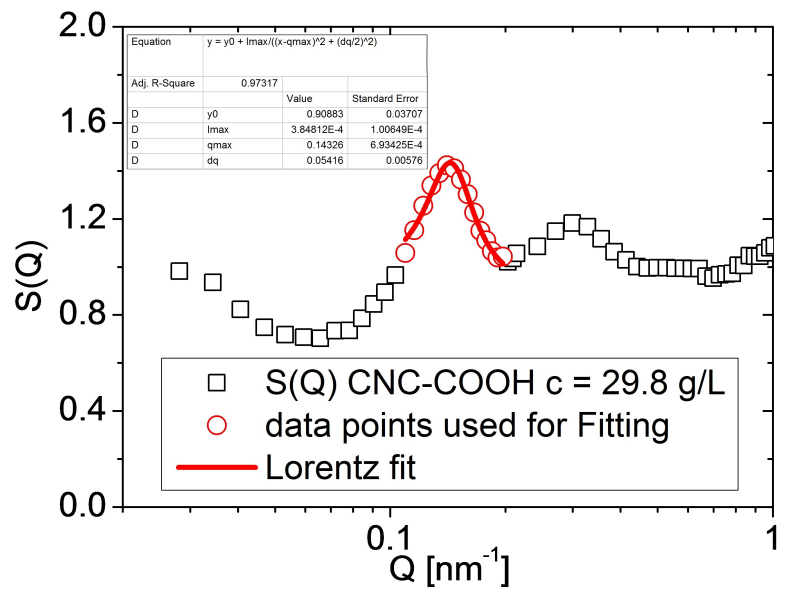

Figure 7: An Example of the Lorentz fit to extract $Q_{\max }$. 
Table 11: Concentrations, corresponding number densities and varying parameters of the modified Caillé structure factor used together with the parallelepiped model for $\mathrm{CNC}_{-} \mathrm{SO}_{3} \mathrm{H}$ samples.

\begin{tabular}{|c|c|c|c|c|}
\hline$c[\mathrm{~g} / \mathrm{L}]$ & 2.3 & 9.1 & 27.3 & 45.5 \\
\hline Number density $\left[10^{-7} \cdot \mathrm{nm}^{-3}\right]$ & 0.12 & 0.48 & 1.44 & 2.47 \\
\hline$d[\mathrm{~nm}]$ & 141.8 & 83.1 & 48.8 & 37.5 \\
\hline$\eta$ & 1.11 & 1.07 & 0.97 & 0.92 \\
\hline$N u$ & 1.67 & 0.85 & 0.40 & 0.16 \\
\hline
\end{tabular}

\section{Statistical Analysis}

A Log Norm distribution was used to describe the polydispersity of the system. Here $\mu$ is the location parameter and $\sigma$ is the scale parameter.

$$
f(x)=\frac{1}{(\sqrt{2 \pi} \sigma x)} e^{\frac{\left(-\ln (x)-\mu^{2}\right)}{\left(2 \sigma^{2}\right)}}
$$

Furthermore, the following equation was used for the extraction of the mean value.

$$
x_{\text {mean }}=e^{\mu+\frac{\sigma^{2}}{2}}
$$

\section{Additional AFM data}

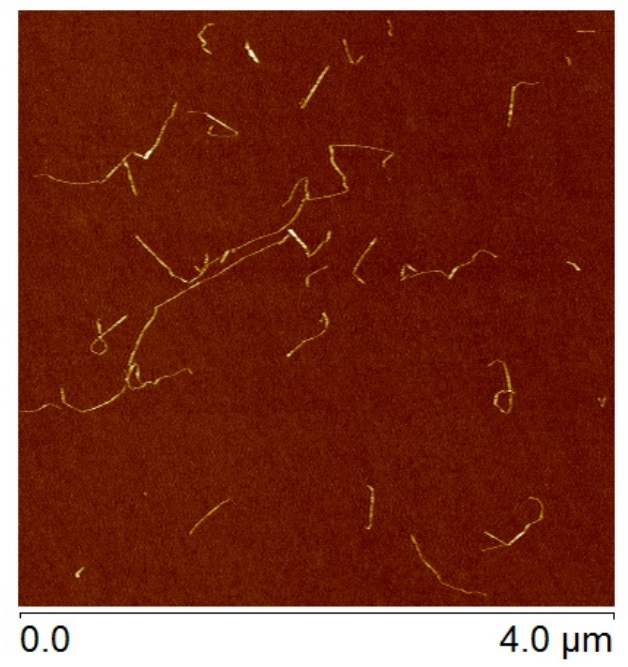

$5.0 \mathrm{~nm}$

$-4.0 \mathrm{~nm}$

Figure 8: CNF-COOH, starting material for CNC-COOH preparation, showing its fibrillar shape. 


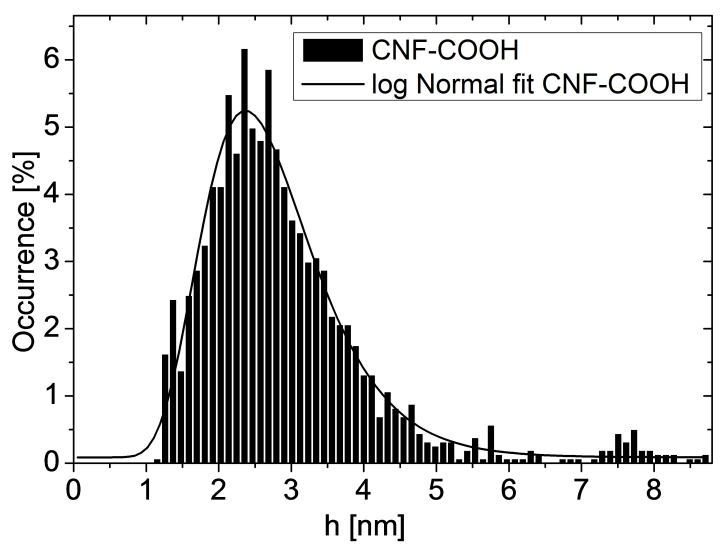

Figure 9: AFM height distributions from individual particles of CNF-COOH fitted with a log-normal distribution function. From the fit an average particle height of $2.5 \mathrm{~nm}$ was found.

A log-normal distribution function was used to describe the AFM data. For CNF-COOH $\sigma=0.33$ and $\mu=0.86$ was found. This gives an average particle height of $2.5 \mathrm{~nm}$ for CNF-COOH. The inset of Fig. 10 shows height profiles across three clusters of CNC-COOH aggregates.
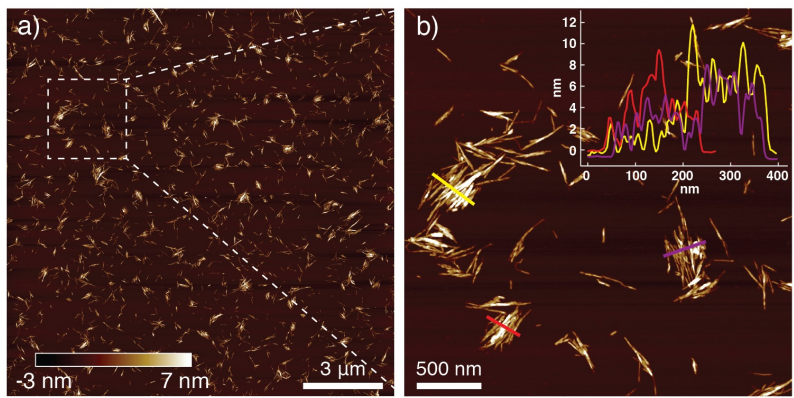

Figure 10: AFM image of CNC-COOH showing single crystal aggregates. The inset of panel b shows the height distribution across 3 clusters of crystal aggregates.

\section{Aggregate interactions and packing}

The ionic strengths $I$, of the aggregate dispersions were estimated from the total number of available counterions as given by the product of the charge density (in mol/g) and the aggregate concentration (in $\mathrm{g} / \mathrm{L}$ ). For example, the CNC-COOH sample at $10.9 \mathrm{~g} / \mathrm{L}$ has an 
estimated ionic strength of $0.36 \mathrm{mmol} / \mathrm{g} \cdot 10.9 \mathrm{~g} / \mathrm{L}=3.9 \mathrm{mmol} / \mathrm{L}$. To estimate the overlap aggregate volume fraction, the following expression was used: $\Phi_{O L}=(h / L)^{2}=a^{-2}$ where $h$ is the height of the aggregate, $L$ is the length of the aggregate and $a$ is the aggregate aspect ratio. From the aggregate dimensions the overlap concentration for $\mathrm{CNC}-\mathrm{COOH}$ and $\mathrm{CNC}-$ $\mathrm{SO}_{3} \mathrm{H}$ can be estimated to $0.1 \mathrm{~g} / \mathrm{L}$ and $0.5 \mathrm{~g} / \mathrm{L}$ respectively. If the aggregates are distributed uniformly in space, the average distance between the aggregates can be estimated from the aggregate number density, $n$, as: $d=n^{-1 / 3}$. This gives the scaling exponent $-1 / 3$ for space filling of aggregates used as comparison in Fig. 7b.

The Debye length was calculated using equation 3, where the ionic strength, I, has been estimated from the concentration of counter ions in the samples.

$$
\frac{1}{\kappa}=\sqrt{\frac{\epsilon_{r} \epsilon_{0} k T}{2 N_{A} e^{2} I}}
$$

Here $\epsilon_{r}$ is the dielectric constant, $\epsilon_{0}$ the permittivity of free space, $k$ the Boltzmann constant, $T$ the temperature in Kelvin, $N_{A}$ the Avogadro number and $e$ the elementary charge.

Table 12 shows the CNC-COOH cluster size, in the form of the hydrodynamic diameter extracted from DLS, during increasing CNC aggregate concentration followed by dilution. The results show the reversibility of the CNC-COOH cluster formation.

Table 12: Hydrodynamic diameter extracted from DLS data for CNC-COOH for varying $\mathrm{CNC}$ aggregate concentrations before and after dilution.

\begin{tabular}{|c|c|c|c|}
\hline & $Z_{a v g}\left(D_{h}\right)$ & $\mathrm{c}(\mathrm{g} / \mathrm{L})$ & remark \\
\hline original sample & 102 & 0.1 & \\
\hline after upconcentration & 886 & 35 & \\
\hline after dilution & 174 & 0.1 & no stirring \\
\hline after dilution & 136 & 0.1 & stirring over night \\
\hline
\end{tabular}

